\title{
Evaluating an undergraduate interprofessional education session for medical and pharmacy undergraduates on therapeutics and prescribing: the medical student perspective
}

\author{
This article was published in the following Dove Press journal: \\ Advances in Medical Education and Practice \\ 5 December 2016 \\ Number of times this article has been viewed
}

\section{Bethany M Shelvey' \\ Sion A Coulman ${ }^{2}$ \\ Dai N John²}

'School of Medicine, ${ }^{2}$ School of Pharmacy and Pharmaceutical Sciences, Cardiff University, Cardiff, Wales, UK

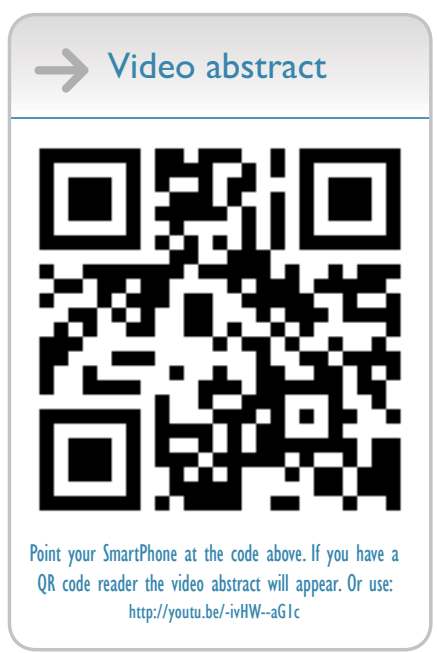

Correspondence: Dai $\mathrm{N}$ John School of Pharmacy and Pharmaceutical Sciences, Redwood, Cardiff University, King Edward VII Avenue, Cardiff CFIO 3NB, UK

Tel +442920875804

Fax +44292087 4I49

Email Jondn@cardiff.ac.uk
Background: The current literature on undergraduate interprofessional education (IPE) for pharmacy and medical students highlights a range of positive outcomes, although to date IPE has focused predominantly on student views and experiences of IPE sessions with these opinions being sought at the end of the sessions. This study aimed to evaluate medical students' experiences of therapeutics and prescribing IPE, with pharmacy students, 1 year following the session. Methods: Following ethics committee approval, 3rd year medical students at Cardiff University were invited to participate using non-probability sampling. Topic guide development was informed by the literature and research team discussions, including a review of the materials used in the IPE session. Semi-structured one-to-one interviews explored experiences, prior to, during, and after the IPE session. Interviews were audio-recorded, transcribed verbatim, and analyzed thematically.

Results: Eighteen medical students were interviewed; 11 were females. Seven themes were identified, namely 1) refinement of pre-session preparation, 2) session value, 3) learning with a pharmacy student, 4) learning about a pharmacist, 5) learning from a pharmacy student, 6) importance and application of what was learnt into practice, and 7) suggestions for change.

Conclusion: This study provides a valuable insight into medical students' experiences of a therapeutics and prescribing IPE session and emphasizes the value they placed on interaction with pharmacy students. Medical students were able to recall clear learning experiences from the IPE session that had taken place 12 months earlier, which itself is an indicator of the impact of the session on the students. Furthermore, they were able to describe how knowledge and skills learnt had been applied to subsequent learning activities. Those developing IPE sessions should consider the following: clarify professional roles in the session content, incorporate IPE as a series of activities, and use small groups of students to optimize student-student interaction and active learning.

Keywords: learning, case-based, medical education, pharmacist, qualitative research, thematic analysis

\section{Introduction}

A commonly used definition for interprofessional education (IPE) is provided by the UK Centre for the Advancement of IPE (CAIPE)1: "Interprofessional Education occurs when two or more professions learn with, from, and about each other to improve collaboration and the quality of care." ${ }^{2}$ IPE is a broad term encompassing initiatives between professionals in the workplace and between students in universities and other 
settings. ${ }^{3}$ The first IPE programs within healthcare were pioneered around 40 years ago in North America and Europe. ${ }^{3}$ IPE was formally endorsed by the World Health Organization 20 years later. ${ }^{3,4}$ This generated an increased interest in IPE among researchers, educators, and policy makers. ${ }^{5}$ The current interprofessional (IP) medicine and pharmacy therapeutics and prescribing literature have focused predominantly on student views at the end of, or shortly following, individual IPE sessions. A number of studies reported that medical students showed a positive change in perception of the role of another profession following IPE. ${ }^{6-15}$ Vrontos et al reported that perception of a pharmacist's role improved significantly among other healthcare students following a 1 day IPE event, ${ }^{6}$ and others have found that IPE positively moderated stereotypical beliefs. ${ }^{16}$

Research suggests that IPE also has positive effects on collaboration among students. ${ }^{7,10,17-19}$ Curran et al reported a significant and continual improvement in attitudes toward teamwork in medical students following IPE. ${ }^{10}$ Knowledge change, related to the IPE topic, was another reported positive outcome, but few studies have demonstrated a significant increase in this outcome. ${ }^{20-22}$ Taylor et al reported findings following an interactive pediatrics prescribing workshop where medical student confidence in prescribing increased in both IP and uniprofessional groups but with no significant difference in knowledge of prescribing when the IP group was compared to the medic only group. ${ }^{21}$

Gilligan et al found that IPE sessions which promoted interaction and engagement between participants were valued highly, ${ }^{23}$ and Curran et al reported that students were more highly satisfied with face-to-face IPE compared to that online. ${ }^{24}$ Rosenfield et al demonstrated that even when face-to-face, a large-scale activity can limit the amount of IP interaction. ${ }^{25}$ Overall, much of the literature suggested that students' attitudes toward IPE were positive ${ }^{9,13,18,21,22,24-26}$ although a small number of studies have identified medics as more negative than other professions who participated. ${ }^{17,27,28}$ Odegard et al identified some practical issues associated with implementing and sustaining IPE sessions including the need for an appropriate physical space. ${ }^{18}$ Issues such as differences in curricula, scheduling, and intended learning outcomes also need consideration with potential solutions having been suggested. ${ }^{8,18}$

The current literature on undergraduate IPE primarily reports the opinions and satisfaction of participants regarding specific IPE and their views on the potential advantages of IPE. In a recent review of IPE, it was highlighted that the need for more evidence on the most efficient and effective ways of delivering "pre-registration IPE... including the evaluation of student experience" was required. ${ }^{29}$

\section{Cardiff University's context for undergraduate medicine-pharmacy IPE}

The importance of prescribing and therapeutics in medical curricula is reinforced by the UK regulator for medicine, the General Medical Council (GMC). The GMC requires undergraduate medical curricula to be designed to ensure that graduates are competent in prescribing. ${ }^{30}$ Reasons in part were due to findings showing that some junior doctors lacked the clinical pharmacology and therapeutics knowledge required of them. ${ }^{31,32}$ Hospital medication error rates of $8 \%-10 \%$ were made by doctors in the first 2 years after their initial medical degree. ${ }^{33}$ Potentially lethal errors occurred in almost $2 \%$ of the medication orders in the EQUIP study with pharmacists intercepting and preventing these errors before patients were harmed. ${ }^{33}$ Closer working between general practice doctors and community pharmacists to improve prescribing and medicines safety has also been advocated. ${ }^{34}$ These findings support the principle that patient safety is a shared responsibility of the healthcare multidisciplinary team (MDT) $)^{33,34}$ and IPE at undergraduate level should help develop IP working. ${ }^{35-37}$

An IPE session was conducted with 3 rd year medical and either 3rd or 4th year pharmacy students at Cardiff University in the United Kingdom (UK). Year cohorts consisted of $\sim 260$ medical students and 125 pharmacy students, hence was the requirement to use students from both $3 \mathrm{rd}$ and 4 th years of the pharmacy program at Cardiff. The medical degree at Cardiff is 5 years in duration, whereas the pharmacy degree is a 4-year program. The 2-hour session focused on therapeutics and prescribing, and facilitators assisted the IP student pairs/ trios, who worked together to complete a series of clinical cases. At the time of this session, this was the only formal IPE session conducted between pharmacy and medical students. The current Cardiff undergraduate medical degree has formal IPE embedded in each of the 5 years of the curriculum. Sessions took place in a large, tiered lecture theatre with a total of $\sim 160$ students together with 6 facilitators (medics and pharmacists). The cases involved medicines history taking, identification of drug-drug interactions and adverse drug reactions (ADRs), ADR reporting and prescription writing as well as requiring problem solving and decision making. IP partners alternated role-playing the patient and the health professional. The session outcomes of case-based IP working were as follows: 1) to establish an accurate drug 
history, covering both prescribed and other medication, 2) to plan appropriate drug therapy, 3 ) to provide a safe and legal prescription, and 4) to detect and report ADRs.

Each of the three cases used in the session required the use of the British National Formulary (BNF). ${ }^{38}$ The BNF is a resource widely used by health professionals in the UK involved with prescribing, monitoring, supplying, and administering medicines. It provides authoritative, independent information of the selection of safe and effective medicines for individual patients. The case-based session was designed so that interactions between medical and pharmacy students would facilitate learning about each other's respective strengths and weaknesses in selecting appropriate medicines for individual patients.

To address the gap in the literature on participants' views of IPE in the longer term, the aim of this study was to evaluate Cardiff University 3rd year medical undergraduate student experiences of a case-based therapeutics and prescribing IPE session with pharmacy undergraduates 1 year following the IPE session. The study objectives were to explore 1) student preparedness for the session, 2) utility of the session including specifically working with pharmacy students, 3) application of learning since the IPE session, and 4) suggestions for change for future cohorts.

\section{Methods}

A qualitative design was selected due to the exploratory nature of this research and its aim. Student views were obtained via semi-structured, one-to-one interviews, undertaken by the same researcher. In accordance with a semi-structured approach, a list of topics and questions was developed to guide the interviews; neither the wording nor the order of the questions was predetermined..$^{39,40}$ The interviews were undertaken by an intercalating medical student 1 year following the session. This medical student had participated in the session a year earlier, and therefore, before data collection was commenced the student wrote a reflective account of their views and experiences so as to raise awareness of their potential biases to themselves and other members of the research team. The 1 year interval was selected to provide students with an opportunity to apply any learning during subsequent clinical placements and/or other learning. A topic guide was developed following a review of the literature and research team discussions, including those relating to the sessions and the cases used. It consisted of the following: recall of the 2013/14 IPE session (including a prompt of case topics if necessary), preparedness for the session, session activities, feedback after the session, use of subsequent IPE session knowledge/skills, valuable aspects of the session, suggestions for improvement, other views on session, and any other comments on IPE more broadly. The study was approved by Cardiff University's pharmacy research ethics committee. Interviews were audiorecorded, transcribed verbatim, and anonymized. Participants were provided with a participant information sheet prior to the interview. Written informed consent was obtained from each participant.

Those medical students who were in their 3rd year of study in 2013/14 (when the IPE sessions were conducted) were invited to participate in $2014 / 15$ via a closed social media group (Facebook ${ }^{\circledR}$ ). Purposive and convenience sampling were used as was snowball sampling. ${ }^{41}$ Other than one conducted via FaceTime ${ }^{\circledR}$, interviews were conducted face to face in a location convenient to the interviewee (a private room in university or the individual's home).

A pilot interview was carried out with a view to reviewing the topic guide and amending, if necessary. This pilot transcript was included in the data set and analyzed as only two amendments were required, namely 1) prompting as to the nature of the cases used and 2) asking about attendance at the session by their peer group. IPE materials used during the sessions were provided to remind interviewees of session context, as necessary. Six interviews were transcribed by the interviewer and the remaining ones were transcribed, anonymously and under a confidentiality agreement, by a commercial organization. All transcripts were carefully checked against the audio recording by the interviewer twice to ensure accurate transcription. Thematic analysis was used with semantic themes within an essentialist epistemology. ${ }^{42}$ Prior engagement with the literature is often considered contradictory to this approach. However, Tuckett argued that it can enhance sensitivity to subtle features in the data. ${ }^{43}$

\section{Data analysis}

The six-step process of inductive thematic analysis, outlined by Braun and Clark, was used to guide analysis. ${ }^{42}$ Following verification of the accuracy of the transcripts, open coding was performed line by line for each transcript. Words, phrases, and/or sections of text that represented a fundamental unit of meaning were assigned to codes within each transcript. The coding was reviewed across transcripts to ensure that the same codes had been applied consistently. Themes were identified from the codes. Themes were also reviewed for consistency across the entire data set by the interviewer, and these were confirmed by the other members of the research team, thus increasing trustworthiness to increase reliability. The themes were then grouped into three sections, namely prior to the 
IPE session, during the IPE session, and post IPE session. The results section describes the data set within and across themes, providing data extracts to illustrate the nature of each, which were confirmed by each member of the research team as being appropriate for the theme. At each stage, the medical student interviewer and other members of the research team reflected on their potential biases and experiences during the data analysis stages.

\section{Results}

Interviews were conducted with 18 medical students, 11 of whom were females. The duration of interviews ranged from 12 to 25 minutes. Analysis of the interview transcripts resulted in identification of seven themes, namely 1) refinement of pre-session preparation, 2) session value, 3) learning with a pharmacy student, 4) learning about a pharmacist 5) learning from a pharmacy student, 6) importance and application of what was learnt into practice, and 7) suggestions for change (Table 1).

\section{Theme I: refinement of pre-session preparation}

\section{Value of preparation and expectations}

When focusing on student experiences prior to the session, it became evident that none of the students interviewed had undertaken any specific preparation for the IPE session; 16 of the 18 were also unsure what to expect from the session exactly. Students reported that with more preparation they could have benefited more from the session:

I think some teaching before the session would be quite useful, because then you'd sort of know what to expect a bit more and... be able to contribute a bit more. [009]
Need for concise, relevant pre-session information clarifying session aims

Few students recalled reading the pre-session information email, but when showed it during the interviews they were able to identify aspects that they deemed to be useful. A number of students believed it was important that the session aims had been identified prior to the session. Participants also indicated it was beneficial that there was emphasis on the importance of the IPE session, that is, in terms of its relevance to the medical student's future career:

...it's good that it gives us the reasoning for why we have the tutorial particularly because it's scary that junior doctors may prescribe incorrectly. [013]

Many participants stated the pre-session information could be improved by ensuring that it was more concise, for example:

...shorten it and bullet point things because people don't...

if you saw something that length you might just not read

it. [012]

\section{Need for preparatory work}

Many participants felt it would be beneficial to introduce preparatory work for future cohorts. A number of these participants felt delivery via online e-learning materials would have been effective:

I also think there should have been a preparation task we had to do so an e-learning module and something interactive, a quiz maybe. I think by doing a bit of work in the topic area before I would have got more out the session then. [001]

Table I Themes and subthemes identified using thematic analysis

\begin{tabular}{|c|c|c|}
\hline Section & Theme & Subthemes \\
\hline \multirow[t]{3}{*}{ Prior to session } & Refinement of pre-session preparation & Value of preparation and expectations \\
\hline & & Need for concise, relevant pre-session information clarifying session aims \\
\hline & & Need for preparatory work \\
\hline \multirow[t]{7}{*}{ During session } & Session value & Varied and relevant cases \\
\hline & & Interprofessional student-student interaction \\
\hline & Learning with a pharmacy student & Pharmacy students have superior knowledge of medicines and the BNF \\
\hline & & Pharmacy students have a more structured approach to medicines problem solving \\
\hline & Learning about a pharmacist & \\
\hline & Learning from a pharmacy student & Increased knowledge of the BNF \\
\hline & & Learning from a pharmacy student's approach to medicines history taking \\
\hline \multirow[t]{5}{*}{ Post session } & Importance and application of what was & Structured medicines history taking \\
\hline & learnt into practice & Effective use of the BNF \\
\hline & & The importance of good medicines knowledge in the medical degree and future career \\
\hline & Suggestions for change & Further IPE welcomed \\
\hline & & Smaller cohort size would be more beneficial \\
\hline
\end{tabular}

Abbreviations: BNF, British National Formulary; IPE, interprofessional education. 


\section{Theme 2: session value}

Varied and relevant cases

The next section of the interviews explored student experiences during the session. A number of students commented favorably on the use of case-based learning:

I think case-based learning generally is useful to put knowledge into context. [007]

Participants also discussed which particular aspects of the cases they valued. Three cases were used in the session, and a number of participants believed that this variety of clinical scenarios was appropriate. Other students commented positively on the relevance of the clinical content to their degree and future career:

I think the cases were all fairly relevant. And sort of... sort of fairly useful and applicable and like things you'd recognize coming up in your own exams. [004]

...they were relevant. I think it's something that you come across every day as an F1 (first year of a 2-year foundation program post-graduation) or as any doctor in any specialty. [008]

\section{IP student-student interaction}

Seventeen of the 18 participants commented positively on the opportunity for interaction with a pharmacy student partner; the remaining student did not mention this point specifically. Many students felt that this style of learning was more effective than didactic methods:

I think it was good that we were paired with a student rather than being taught it from the front of a lecture theatre. You could concentrate more and you wouldn't stop concentrating if you were physically talking to an individual. [007]

A number of participants also identified the value of interacting with a pharmacy student as a future member of the healthcare MDT:

...it was a good idea just to pair up because I know we're going to have to work with pharmacists throughout like our careers. [012]

\section{Theme 3: learning with a pharmacy student}

It was considered key to ask specifically on IP interactions and not solely on the valuable aspects of the session itself. As defined by CAIPE: "Interprofessional Education occurs when two or more professions learn with, from, and about each other."2

\section{Pharmacy students have superior knowledge of medicines and the BNF}

A number of participants reported that the pharmacy student's knowledge of medicines and how to use the BNF was greater than their own:

I did feel like they had a better knowledge of the BNF than I did... [003]

I think they were more knowledgeable about the drugs than I was in that session. [013]

\section{Pharmacy students have a more structured approach to medicines problem solving}

Working alongside pharmacy students to solve case-based patient problems led some of the participants to believe that their own approach was less well organized. They observed the pharmacy students applying a logical, structured approach to problem solving:

...they obviously have like a regimented like way of asking things which is better than what we, sort of, just pick randomly... [012]

I think they have a very different knowledge base to us. Ours is more clinical whereas theirs is a bit more practical and a bit more logical. So it helps you approach things in a logical way. [010]

\section{Theme 4: learning about a pharmacist}

Students had divided opinions on whether or not the IPE session enabled them to learn about a pharmacist's role. However, some reported that the session increased their understanding of this role:

I guess it sort of just makes you more aware of the job they do though from speaking to, from sort of being there with them. [004]

Many students believed that learning more about a pharmacist's role would have been beneficial, suggesting it could be a focus for future IPE sessions:

...maybe that could be more of an emphasis in future sessions. I thought even though they taught me a lot I'm not really sure if I found out what they did. [007]

I think had I come away with a better understanding of the part to play the pharmacist has then that would have been more beneficial. [015]

Several students reported that learning about their pharmacy student partner had resulted in a positive attitude change towards pharmacists: 
...I think it's only just sort of like strengthened my positive view of pharmacists. [015]

Participants reported having a greater understanding of a pharmacist's point of view and felt they would be more likely to approach them for help in the future:

I think I would like to think that I could, sort of, see where they were coming from. If a problem arose I wouldn't be so sort of closed to their thoughts on a problem. I'd respect their input... [007]

...if I was on a ward as a doctor and I wasn't really sure if I was prescribing the right thing. I'd feel more confident in going to them and being like okay is this right? [005]

\section{Theme 5: learning from a pharmacy student \\ Increased knowledge of the BNF}

Many students explained, as a result of the session, their knowledge of how to use the BNF had increased; a large proportion of these students also specified that this was a result of being taught by their pharmacy student partner:

The pharmacy student helped me a lot in realizing how to use the BNF. [001]

\section{Learning from a pharmacy student's approach to medicines history taking}

Another area in which they had benefitted from working with a pharmacy student was in medicines history taking. A number of participants reported that interacting with or observing their partner helped them to learn how to improve their approach:

I think it was seeing the pharmacist student taking a history. Like that's the thing I remember the most, and I think I probably would have taken from that is to be more thorough with a drug issue. [012]

\section{Theme 6: importance and application of what was learnt into practice}

When looking at student experiences following the session we wanted to explore if the knowledge of using the BNF and the skill of medicines history taking, described above in "Learning from a pharmacy student", had been applied by the students to practice.

\section{Structured medicines history taking}

The most common skill that students reported applying since the IPE session was taking a structured medicines history; students reported finding an opportunity to do so during a compulsory medication review in a placement in the 4 th year of the medicine curriculum:

We had to go through all the medications and worked out any interactions or anything that could be dropped [...] So it was just helpful to have an introduction to it really. [018]

\section{Effective use of the BNF}

A number of students also identified instances, following the session, when they had been able to use the BNF effectively:

Looking at and even using the BNF on placement or using it back at home to revise from. I think that that's been useful as well because I wouldn't have known how to use it beforehand... [008]

I remember using the BNF afterwards and being better at it and being able to actually find drugs, whereas before I would have taken a lot longer. [010]

The importance of good medicines knowledge in the medical degree and future career

Fifteen of the 18 participants explained how important future application of the knowledge and skills would be for them. In terms of their degree a number of students believed that the session would be helpful when preparing for a prescribing assessment:

In terms of degree, I think it will be useful for your prescribing skills exam in fifth year. [010]

With regard to their future career, a number of students identified the importance of applying what they had learnt in order to try and reduce medication error rates and improve patient safety:

...it will make me more confident when I do come to prescribing and when I learn more about prescribing. And that I'm not doing any damage as well. [001]

...drug interactions and stuff is one of the main causes of like doctor induced injuries, isn't it? So obviously it would be... it should be something that you'd be looking at. [012]

\section{Theme 7: suggestions for change}

\section{Further IPE welcomed}

Seventeen of the 18 students indicated that IPE sessions would be worthwhile attending in the future, whereas the other student remained neutral. Many believed that there should be an increase in the number of IPE sessions offered as the one IPE session they had experienced had been valuable: 
...if it's a one off thing people just think well it's not that important. If it was something that built in systematically then you think it's important. [012]

Others felt that students would gain more from multiple sessions:

... say there's three sessions and everyone has to attend three sessions, and they're just an hour, one each month or something, you'd felt like you'd got more from it. [005]

...so I think when you've sort of got more of a grasp of the clinical aspect of medicine then it would be useful afterwards as well. Cos that's when you are thinking more in detail about prescribing. [001]

Students wanted IPE sessions introduced earlier in the curriculum:

I think it is good especially if you're starting at med school because you know, like, interprofessional learning continues throughout especially with your career. So it's good to start when you're learning your basics to get you used to it. [009]

A number of participants felt that early introduction was particularly important due to the evolving medical degree at Cardiff, ${ }^{44}$ which exposes students to clinical placements earlier:

First year onwards cos I think first years get more placement now on [the new degree program] anyway so they're gonna be exposed to all this a lot earlier. [004]

\section{Smaller cohort size would be more beneficial}

Participants were asked to identify aspects of the session that could be improved. The lecture theatre as a venue was too large and the seating arrangements were not suited to role-play:

I didn't like the big lecture theatre. I hated that. It was just loads of people. [005]

The fact that it was in a lecture theatre wasn't great because you had to... it's not a very natural way of talking to somebody, sort of sitting sideways which wasn't good. [011]

Some students suggested that reducing class size would alleviate the disadvantages of a tiered lecture theatre:

I would say maybe make it more of a tutorial led thing rather than a big lecture theatre, because I just think it was too busy. [016]

In total, 14 of the 18 participants specifically stated that reducing number of students in the class would be beneficial. There would be more opportunity to interact with facilitators, and allocation of students to IP pairs would be more straightforward:

I think it obviously would have made the organization a lot easier cos there would be a lot less people [003]

Small group teaching is always much better because it sort of breaks down barriers with the educator. I mean, you feel like you can ask questions a lot easier, like you know building that sort of rapport up. [011]

\section{Discussion}

Eighteen undergraduate medical students were successfully recruited and were interviewed. Medical students were able to recall the IPE session with pharmacy students 1 year following. This was the only IP teaching session this cohort of medical students experienced with pharmacy students, and this may have been a reason for their ability to recall the session 1 year later. The interviewer was a medical student, and this may have resulted in potential subjects agreeing to participate. Another potential reason was that students may have wanted to contribute to the development of the curriculum to help future cohorts. The possibility of interviewer bias as a medical student, however, cannot be ruled out. ${ }^{45}$

During exploration of subjects' views on preparedness for the IPE session, some reported feeling underprepared. Other researchers have also found that some students felt they were not prepared for such a session. ${ }^{27}$ The use of a preIPE meeting together with an online forum was considered effective at preparing students for the IP element in that it helped break down barriers between the professions. ${ }^{29}$ The use of a blended approach to IPE, using online and face-toface approaches, is one advocated in several reports. ${ }^{29,46,47}$ When asked about the preparatory information, a number of students indicated the value of outlining the session aims, as has been shown by others. ${ }^{46-48}$

With regard to the session itself, participants spoke favorably about the case-based approach which supports findings of other researchers. ${ }^{24,49}$ Students also reported that interacting with a pharmacy student, and future MDT member, was a valuable experience, a finding also reported elsewhere. ${ }^{20,23}$

Following the IPE session in this study, many students reported examples of how they had been able to apply elements of learning to subsequent activities and experiences. The two most commonly applied skills, structured medicines history taking and effective use of the BNF to identify safe and effective medicines for a patient, were those skills students had learnt or developed from their pharmacy partner. Within the current literature, there is limited evidence on 
transfer of outcomes to clinical practice following IPE due to the complexity, including the longitudinal nature of such studies. ${ }^{9,46,50}$ However, we are able to describe, in this paper, students self-reporting positive benefits from the IPE session.

Students in this study would welcome further IPE, supporting the view of others, for example, that IPE should be integrated into course programs, rather than running stand-alone sessions..$^{23,51}$ It is important that the sessions and intended learning outcomes of such sessions are appropriate and those early on in the degree may benefit from a focus on an element that does not require in-depth, specific knowledge and/or skills. One such approach might be based on teamwork skills. ${ }^{17,52}$ The views of the students about this IPE session on class size, interactivity, problem-solving, explicit relevance of cases to future professional roles, and access to/interaction with facilitators align with those of others reporting IPE evaluations ${ }^{25,29}$ and also with the general principles of promoting learning within higher education. ${ }^{53}$

Limitations of this study include the relatively small number of participants from a single cohort at one university and that participants were self-selecting. Non-response bias is not known, which was another limitation. Social desirability bias $^{54}$ may also have been an issue although it was anticipated that the use of a student interviewer would have mitigated this to a lesser extent than if we had used a member of faculty to conduct the interviews. While follow-up after 12 months provided the students with an opportunity to evaluate their IPE in the context of their subsequent practice experience, there was a potential risk of recall bias. However, respondents were able to recall the sessions and at least some learning from the session, probably due to the session being their only IP learning with pharmacy students. This was not recognized as an issue by the medical students, who demonstrated recall of sessions and cases, for some following brief prompts, during interviews. The 12-month interval was selected as a time that would permit meaningful application of learning to subsequent sessions that were not too distant from the IPE learning event. Individual members of the research team had their own experiences and viewpoints on IPE and these were recognized and discussed throughout the process.

The study participants did offer views and suggestions that could also be of potential utility by others who have introduced, or are considering introducing, IPE. ${ }^{55}$ Overall, the interviews achieved the study aim and objectives and have resulted in changes being made to the IPE therapeutics and prescribing session for future cohorts. The sessions now take place in flat, workshop rooms with 40-50 students and 3-4 facilitators per group. The use of IP partners, role-play, and
Table 2 Suggested recommendations for those considering introducing, evaluating, or reviewing IPE

I. Clarify professional roles in IPE session content: Ensure that alongside learning about the topic, students are able to learn about the roles of other professions involved.

2. Implement IPE as a series of sessions: Ensure sessions relate to one another and are integrated into the curriculum of each of the professions involved.

3. Manage student expectations: Ensure students are aware of how the sessions are relevant to their degree and/or future career and identify the aims and intended learning outcomes of the session, well in advance. The provision of specific pre-workshop activities tasks may also assist.

4. Use a group size that is manageable within the resources available: Resources include the number of and professions of students and timetables (facilitator, student, and room).

5. Promote optimal IP student-student interaction: Ensure students work in IP pairs, trios, or small groups and that seating arrangements promote interactivity. The use of role-play and feedback are helpful.

6. Relate session content to baseline knowledge: Ensure choice of topic and level of difficulty complements the existing knowledge/experience of the students involved, that is, the principles of constructive alignment ${ }^{53}$ apply.

7. Use case-based, active learning: Ensure cases are relevant to practice and to the role(s) of each of professions represented.

Abbreviation: IPE, interprofessional education.

the cases used were each identified as positive elements, and each of these elements has been retained. Future research will evaluate these sessions from the perspective of the pharmacy undergraduates as well as from those of medical students. Few studies have explored longer term outcomes of IPE, ${ }^{50}$ and therefore, this is an additional area of future study.

The views of medical student stakeholders have helped develop the IPE session, building on the strengths, and addressing areas of weakness. Based on the findings of this study, together with the IPE literature, we propose a number of suggestions that may wish to be considered by higher education institutions and others introducing, evaluating, reviewing, and/or developing IPE (Table 2).

As a result of these findings, the IPE therapeutics and prescribing session at Cardiff has been amended so that significantly smaller numbers of students participate in each session in a flat workshop room which facilitates discussion and interaction between students and between students and facilitators.

\section{Conclusion}

This study provides a valuable insight into medical students' experiences of therapeutics and prescribing IPE session and emphasizes the value they placed on interaction with pharmacy students. As with other studies, medical students identified that they had learnt with, from, and about pharmacy colleagues. ${ }^{2}$ This study has for the first time identified that 
medical students were able to recall learning from a specific IPE session that had taken place 12 months earlier and that they have described how knowledge and skills from this IP session had been applied to subsequent learning activities within their medical education. Our findings indicate that those contemplating developing or reviewing IPE should consider the following issues: clarify professional roles in session content, incorporate IPE as a series of activities, use small groups of students from appropriate professions with sufficient numbers of facilitators to optimize student-student interaction and active learning, and to ensure the principles of constructive alignment ${ }^{53}$ apply. Future research is needed to evaluate the effects of specific IPE on patient outcomes.

\section{Acknowledgments}

The authors gratefully acknowledge Professor Philip Routledge, Cardiff University School of Medicine, and the All Wales Therapeutics and Toxicology Centre for the genesis of this interprofessional session and for his significant input into the design of the session and cases and for his leadership in interprofessional education in therapeutics and prescribing. They would like to thank all the medic and pharmacy faculty who have facilitated sessions. Finally, they thank those study participants who have given their time and their opinions and views which have helped the development of IPE at Cardiff, and they hope beyond.

\section{Disclosure}

The authors report no conflicts of interest in this work.

\section{References}

1. Freeth D. Interprofessional education. In: Swannick T, editor. Understanding Medical Education: Evidence, Theory and Practice. Oxford, UK: Wiley-Blackwell; 2010:81-96.

2. Centre for the Advancement of Interprofessional Education. Defining IPE; 2002. Available from: http://caipe.org.uk/about-us/defining-ipe. Accessed June 9, 2016.

3. Barr H. Interprofessional education. In: Dent JA, Harden RM, editors. A Practical Guide for Medical Teachers. 4th ed. Edinbugh, UK: Elsevier Churchill Livingstone; 2009:187-192.

4. World Health Organization. Learning Together to Work Together for Health. Geneva; 1988. Available from: http://whqlibdoc.who.int/trs/ WHO_TRS_769.pdf. Accessed June 9, 2016.

5. Department of Health. Working Together - Learning Together: A Framework for Lifelong Learning for the NHS. London; 2001. Available from: http://dera.ioe.ac.uk/13612/1/Working\%20together\%20-\%20 learning\%20together\%20dept.\%20of\%20health.pdf. Accessed June 9 , 2016.

6. Vrontos $\mathrm{EB}$, Kuhn $\mathrm{CH}$, Brittain KL. Impact of interprofessional activities on health professions students' knowledge of community pharmacists' role and services. Am J Pharm Educ. 2011;75(8):152.

7. Kilminster S, Hale C, Lascelles M, et al. Learning for real life: patientfocused interprofessional workshops offer added value. Med Educ. 2004;38(7):717-726

8. Hardisty J, Scott L, Chandler S, Pearson P, Powell S. Interprofessional learning for medication safety. Clin Teach. 2014;11(4):290-296.
9. O’Neill BJ, Wyness MA. Student voices on an interprofessional course. Med Teach. 2005;27(5):433-438.

10. Curran VR, Mugford JG, Law RM, MacDonald S. Influence of an interprofessional HIV/AIDS education program on role perception, attitudes and teamwork skills of undergraduate health sciences students. Educ Health (Abingdon). 2005;18(1):32-44.

11. Mellor R, Cottrell N, Moran M. "Just working in a team was a great experience..." - student perspectives on the learning experiences of an interprofessional education program. J Interprof Care. 2013;27(4):292-297.

12. Hall PD, Zoller JS, West VT, Lancaster CJ, Blue AV. A novel approach to interprofessional education: interprofessional day, the four-year experience at the medical university of South Carolina. J Res Interprof Pract Educ. 2011;2(1):49-62.

13. Crutcher RA, Then K, Edwards A, Taylor K, Norton P. Multi-professional education in diabetes. Med Teach. 2004;26(5):435-443.

14. Harward DH, Tresolini CP, Davis WA. Can participation in a health affairs interdisciplinary case conference improve medical students' knowledge and attitudes? Acad Med. 2006;81(3):257-261.

15. Ateah CA, Snow W, Wener P, et al. Stereotyping as a barrier to collaboration: does interprofessional education make a difference? Nurse Educ Today. 2011;31(2):208-213.

16. Hawkes G, Nunney I, Lindqvist S. Caring for attitudes as a means of caring for patients-improving medical, pharmacy and nursing students' attitudes to each other's professions by engaging them in interprofessional learning. Med Teach. 2013;35(7):1302-1308.

17. Horsburgh M, Lamdin R, Williamson E. Multiprofessional learning: the attitudes of medical, nursing and pharmacy students to shared learning. Med Educ. 2001;35(9):876-883.

18. Odegard PS, Robins L, Murphy N, et al. Interprofessional initiatives at the University of Washington. Am J Pharm Educ. 2009;73(4):63.

19. Hasnain M, Koronkowski MJ, Kondratowicz DM, Goliak KL. Training future health providers to care for the underserved: a pilot interprofessional experience. Educ Health. 2012;25(3):204-207.

20. Horsburgh M, Lamdin R. Maori health issues explored in an interprofessional learning context. J Interprof Care. 2004;18(3):279-287.

21. Taylor D, Yuen S, Hunt L, Emond A. An interprofessional pediatric prescribing workshop. Am J Pharm Educ. 2012;76(6):111.

22. Saini B, Shah S, Kearey P, Bosnic-Anticevich S, Grootjans J, Armour C. An interprofessional learning module on asthma health promotion. Am J Pharm Educ. 2011;75(2):30.

23. Gilligan C, Outram S, Levett-Jones T. Recommendations from recent graduates in medicine, nursing and pharmacy on improving interprofessional education in university programs: a qualitative study. $B M C$ Med Educ. 2014;14:52. Available from: http://www.biomedcentral. com/1472-6920/14/52. Accessed June 9, 2016.

24. Curran VR, Sharpe D, Forristall J, Flynn K. Student satisfaction and perceptions of small group process in case-based interprofessional learning. Med Teach. 2008;30(4):431-433.

25. Rosenfield D, Oandasan I, Reeves S. Perceptions versus reality: a qualitative study of students' expectations and experiences of interprofessional education. Med Educ. 2011;45(5):471-477.

26. Nango E, Tanaka Y. Problem-based learning in a multidisciplinary group enhances clinical decision making by medical students: a randomized controlled trial. J Med Dent Sci. 2010;57(1):109-118.

27. Anderson E, Thorpe L, Heney D, Petersen S. Medical students benefit from learning about patient safety in an interprofessional team. Med Educ. 2009;43(6):542-552.

28. Jones KJ, Vandenberg EV, Bottsford L. Prevalence, formation, maintenance, and evaluation of interdisciplinary student aging interest groups. Gerontol Geriatr Educ. 2011;32(4):321-341.

29. Centre for the Advancement of Interprofessional Education. Review of Interprofessional Education in The United Kingdom 1997-2013. Fareham, UK; CAIPE: 2014. Available from: http://caipe.org.uk/ silo/files/iperg-review-15-4-14-with-links-pdf.pdf. Accessed June 9, 2016.

30. General Medical Council. Promoting Excellence: Standards for Medical Education and Training. London; 2016. Available from: http://www. gmc-uk.org/education/standards.asp. Accessed June 9, 2016. 
31. Illing JC, Morrow GM, Rothwell nee Kergon CR, et al. Perceptions of UK medical graduates' preparedness for practice: a multi-centre qualitative study reflecting the importance of learning on the job. $B M C$ Med Educ. 2013;13:34. Available from: http://www.biomedcentral. com/1472-6920/13/34. Accessed June 9, 2016.

32. Harding S, Britten N, Bristow D. The performance of junior doctors in applying clinical pharmacology knowledge and prescribing skills to standardized clinical cases. Br J Clin Pharmac. 2010;69(6): 598-606.

33. Dornan T, Ashcroft D, Heathfield H, et al. Final Report: An in Depth Investigation into Causes of Prescribing Errors by Foundation Trainees in Relation to Their Medical Education. EQUIP study; 2009. Available from: http://www.gmc-uk.org/FINAL_Report_prevalence_and_causes_ of_prescribing_errors.pdf_28935150.pdf. Accessed June 9, 2016.

34. Hughes CM, McCann S. Perceived inter-professional barriers between community pharmacists and general practitioners: a qualitative assessment. Br J Gen Pract. 2003;53(493):600-606.

35. Parsell G, Bligh J. Multiprofessional working: learning from experience. Med Educ. 1999;33(9):632-633.

36. Gallagher RM, Gallagher HC. Improving the working relationship between doctors and pharmacists: is inter-professional education the answer? Adv Health Sci Educ Theory Pract. 2012;17(2):247-257.

37. Hawkes G, Nunney I, Lindqvist S. Caring for attitudes as a means of caring for patients - improving medical, pharmacy and nursing students' attitudes to each other's professions by engaging them in interprofessional learning. Med Teach. 2013;35(7):e1302-1308.

38. British Medical Association and the Royal Pharmaceutical Society of Great Britain. British National Formulary. Number 66. London: BMJ Publishing Group; 2013.

39. Hesse-Biber SN, Leavy P. The Practice of Qualitative Research. London: SAGE; 2010:93-130.

40. Merriam SB. Qualitative Research: A Guide to Design and Implementation. San Francisco, CA, USA: John Wiley \& Sons; 2014:87-116.

41. Rubin A, Babbie E. Essential Research Methods for Social Work. 3rd ed. Belmont (MA): Cengage Learning; 2009:131-152.
42. Braun V, Clark V. Using thematic analysis in psychology. Qual Res Psychol. 2006;3(2):77-101.

43. Tuckett AG. Applying thematic analysis theory to practice: a researcher's experience. Contemp Nurse. 2005;19(1-2):75-87.

44. Cardiff University. Introduction to the C21 Curriculum; 2013. Available from: http://medicine.cf.ac.uk/media/filer_public/2013/08/22/c21intro. pdf. Accessed June 9, 2016.

45. Newman I, Benz CR. Qualitative-Quantitative Research Methodology. Carbondale (IL): SIU Press; 1998:57-86.

46. Cooper H, Braye S, Geyer R. Complexity and interprofessional education. Learn Health Social Care. 2004;3(4):179-189.

47. Tosey P. Teaching on the Edge of Chaos. Complexity Theory and Teaching Systems; 2002. Available from: http://epubs.surrey.ac.uk/1195/1/ fulltext.pdf. Accessed June 9, 2016.

48. Parsell G, Bligh J. The development of a questionnaire to assess the readiness of healthcare students for interprofessional learning (RIPLS). Med Educ. 1999;33(2):95-100.

49. Barr H, Koppel I, Reeves S, Hammick M, Freeth D. Effective Interprofessional Education: Argument, Assumption and Evidence. Oxford, UK: Blackwell Publishing; 2005:58-73.

50. Cooper H, Carlisle C, Gibbs T, Watkins C. Developing an evidence base for interdisciplinary learning: a systematic review. J Adv Nurs. 2001;35(2):228-237.

51. Long S, Schwartz BW, Conner-Kerr T, Cada EA, Hogan R. Priorities, strategies, and accountability measures in interprofessional education. J Allied Health. 2014;43(3):e37-44.

52. Davidson L, Lucas J. Multi-professional education in the undergraduate health professions curriculum: observations from Adelaide, Linkoping and Salford. J Interprof Care. 1995;9(2):163-176.

53. Biggs J, Tang C S-K. Teaching for Quality Learning at University. 4th ed. Buckingham, UK: Open University Press; 2011.

54. Donaldson SI, Grant-Vallone EJ. Understanding self-report bias in organizational behaviour research. J Bus Psychol. 2002;17(2):245-260.

55. Noble H, Smith J. Issues of validity and reliability in qualitative research. Evid Based Nurs. 2015;18(2):34-35.
Advances in Medical Education and Practice

\section{Publish your work in this journal}

Advances in Medical Education and Practice is an international, peerreviewed, open access journal that aims to present and publish research on Medical Education covering medical, dental, nursing and allied health care professional education. The journal covers undergraduate education, postgraduate training and continuing medical education

\section{Dovepress}

including emerging trends and innovative models linking education, research, and health care services. The manuscript management system is completely online and includes a very quick and fair peer-review system. Visit http://www.dovepress.com/testimonials.php to read real quotes from published authors. 